adsorption on a free surface. It resembles, rather, the results of Kemball', who found from surfacetension measurements that the adsorption of water vapour on a liquid mercury surface did not extend beyond a monolayer at 95 per cent saturation.

Confirmatory experiments were carried out using the elliptical polarization of light to measure the thickness of water films adsorbed on metal, on diamond and on zine blende surfaces. Again, no evidence was found for heavy adsorption even when the vapour was 90 per cent saturated. The adsorbed layer was at most a few molecular layers in thickness. F. P. BOWDEN

Research Laboratory on the Physics W. R. Throssell

and Chemistry of Surfaces,

Department of Physical Chemistry,

Cambridge.

Jan. 30 .

'Lenher, S., and McHaffie, I. R., J. Chem. Soc., 128, 1785 (1926).

${ }^{2}$ Stromberg, R., Phys. Ber., 11, 602 (1930).

${ }^{3}$ Razouk, R. I., and Salem, A. S., J. Phys. Chem., 52, 1226 (1948).

${ }^{4}$ Henniker, J. C., Rev. Mod. Phys., 21, 322 (1949).

${ }_{5}^{5}$ Bastow, S. H., and Bowden, F. P., Proc. Roy. Soc., A, 134, 404 (1931); 151,220 (1935).

${ }^{8}$ Courtney-Pratt, J. S., Nature, 165, 346 (1950).

" Kemball, C., Proc. Roy. Soc., A, 190, 117 (1947).

\section{Surface Tension of Liquid Metals}

WhEN the available experimental values of the surface tensions of liquid metals are plotted against the reciprocals of the corresponding atomic volumes, the accompanying diagram is obtained. The surface tensions are not known with high accuracy; but it is clear that surface tension is approximately inversely proportional to atomic volume, and that the relationship holds for metals of such widely different types as sodium, bismuth and iron.

There seems as yet no satisfactory theory of the relationship-the early calculation of Frenkel ${ }^{1}$, in which it is implicit, has been shown to be incorrect ${ }^{2}$ but two empirical implications are of interest. First, the surface tension of any metal for which experi-

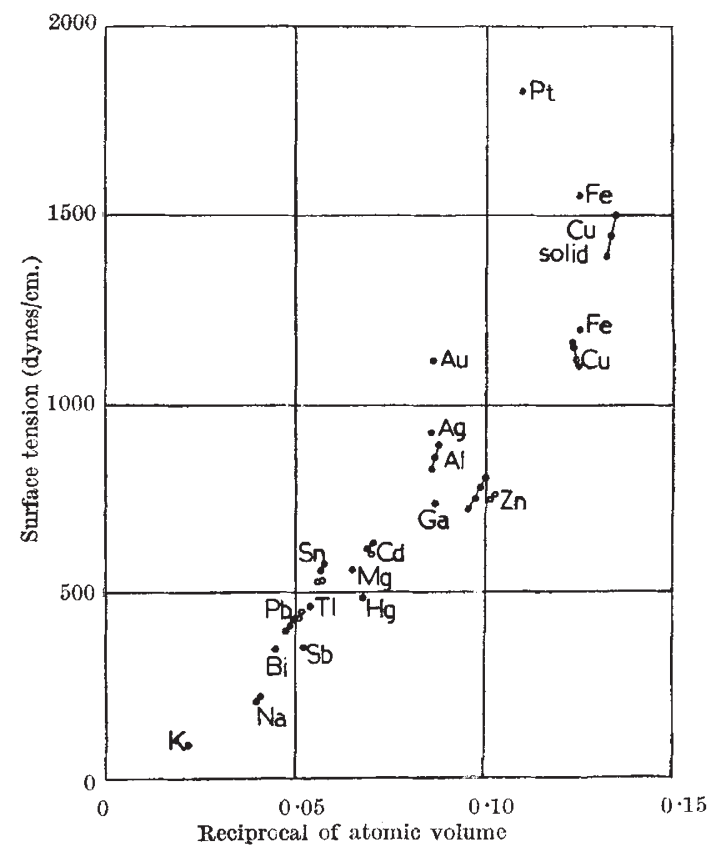

mental surface tension data are unavailable can be approximately assessed from density measurements with an accuracy probably little inferior to that which can at present be obtained by surface tension experiments. Secondly, we have recently shown experimentally, in connexion with metal penetration into compacted sand during sand-casting ${ }^{3}$, that the height of metal that will stand on a sand compact without penetrating into the capillary pores is proportional to surface tension/density and inversely proportional to the effective pore radius; the present relationship coupled with this result leads to the very simple conclusion that the height of metal that will stand on a given sand compact is approximately inversely proportional to atomic weight alone, and that for a sand compact to resist penetration by a particular height of metal, the effective pore radius must be inversely proportional to atomic weight. This may be a matter of importance in the production of sand-castings of metals of high atomic weight.

D. V. Atrerton

Department of Metallurgy,

T. P. HOAR

University of Cambridge. Dec. 8.

${ }^{1}$ Frenkel, J., Phil. Mag.: (vi), 33, 297 (1917).

2 Samoilovitch, A., Acta Physicochem. U.R.S.S., 20, 97 (1945).

${ }^{3}$ Hoar, T. P., and Atterton, D. V., J. Iron and Steel Inst., 166, 1 (1950).

\section{Colour of BeryI}

THе colour of bright emerald-green was first attributed to chromium by Vauquelin ${ }^{1}$; this was questioned by later observers, who found that the emerald lost its chromium content upon ignition, but retained its colour. Borovik ${ }^{2}$ has recently observed that a white mixture of $0.4 \mathrm{gm}$. of powdered beryl and $0.02 \mathrm{gm}$. of scandium oxide gradually becomes dark blue, and concludes that scandium penetrates "into the beryl as deep as its erystal lattice and is responsible for its colour".

On this point, I have analysed spectrographically (by cathode layer arc) seven Indian beryls of different colours-pale red, orange-yellow, apple-green, pale greenish-blue, sapphire-blue, pale blue and bluish. white-and found only in one variety a concentration of scandium of the order of $10^{-3}$ to $10^{-4}$ per cent. The complete absence of scandium (limit of detection $10^{-5}$ per cent) in the six colour types indicates that scandium is not the cause of coloration in beryls. In all the beryls, alkalis are present in traces: rare-earths have been detected only in four varieties.

The colour of such minerals seems to be a phenomenon connected with the crystal distortion due to a combination of factors, which are perhaps affected by impurities. But the fact that the changes of colour of pale blue beryl to light green and of white beryl to pale brown can be produced after long X-ray irradiation suggests that the phenomenon is not simply due to traces of impurities.

Thanks are due to Prof. P. B. Sarkar and Dr. J. W. Whitaker for their interest in the work, and to Dr. W. D. West for kindly supplying the samples.

Fuel Research Institute, Bibhuti MukherJee Dhanbad, Bihar. Nov. 27.

1 Dana, J. D., “The System of Mineralogy”, 406.

${ }^{2}$ Borovik, S. A., C.R. Acaul. Sri., U.R.S.S., 53, 65 (1946) : Amer. Chem. Abs., 41, 4990 (1947). 